\title{
Stem-cell transplants may purge HIV
}

\section{But treatment is too risky for most people infected by the virus.}

\section{Erika Check Hayden}

03 July 2013

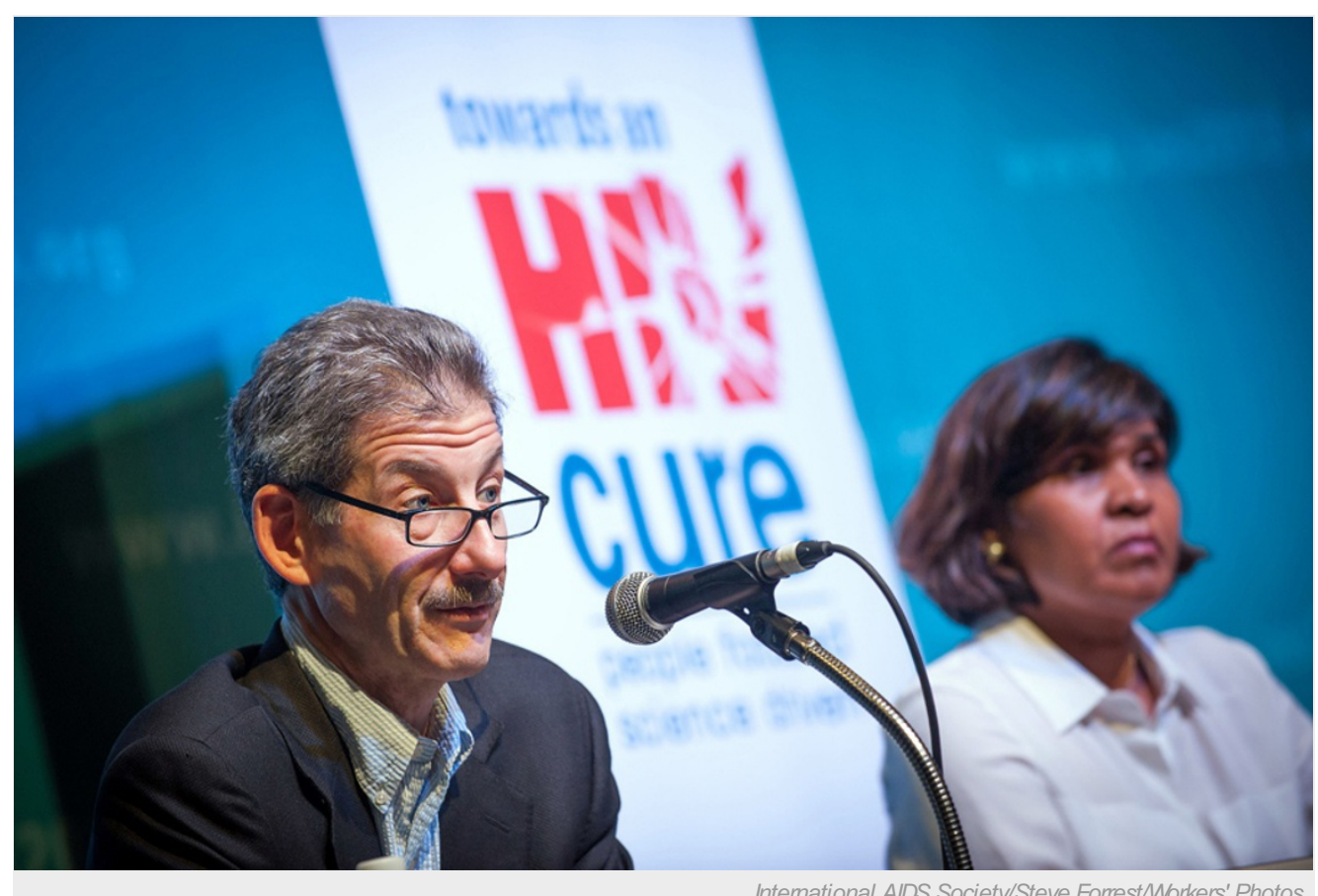

Intemational AIDS Society/Steve Forrest Workers' Photos

Daniel Kuritzkes, a researcher working with two 'Boston patients' who may have been cured of HIV, speaks at an AIDS conference in Kuala Lumpur, Malaysia.

Two men with HIV may have been cured after they received stem-cell transplants to treat the blood cancer lymphoma, their doctors announced today at the International AIDS Society Conference in Kuala Lumpur.

One of the men received stem-cell transplants to replace his blood-cell-producing bone marrow about three years ago, and the other five years ago. Their regimens were similar to one used on Timothy Ray Brown, the 'Berlin patient' who has been living HIV-free for six years and is the only adult to have been declared cured of HIV. Last July, doctors announced that the two men — the 'Boston patients' - appeared to be living without detectable levels of HIV in their blood, but they were still taking antiretroviral medications at that time.

Timothy Henrich, an HIV specialist at Brigham and Women's Hospital in Boston, Massachusetts, who helped to treat the men, says that they have now stopped their antiretroviral treatments with no ill effects. One has been off medication for 15 weeks and the other for seven. Neither has any trace of HIV DNA or RNA in his blood, Henrich says.

If the men stay healthy, they would be the third and fourth patients ever to be cured of HIV, after Brown and a baby in Mississippi who received antiretroviral therapy soon after birth.

But Henrich and Daniel Kuritzkes, a colleague at Brigham who also worked with the men, caution that it is still too early know whether or not the Boston patients have been cured. For that, doctors will need to follow the men closely for at least a year, because the virus may be hiding out in 'reservoirs' - parts of the men's bodies, such as their brain or gut, that can harbour the virus for decades.

"We're being very careful not to say that these patients are cured," Kuritzkes says. "But the findings to date are very encouraging."

HIV researcher Steven Deeks of the University of California, San Francisco, says that doctors might need to wait at least two years before declaring that a cure has been achieved. "Any evidence that we might be able to cure HIV infection remains a major advance," Deeks says. But, he adds, "there have been cases of patients who took many weeks off therapy before the virus took off". 


\section{Exciting news}

Still, researchers and doctors are excited about the news, especially because the Boston patients' treatment differed from the Berlin patient's regimen in one key way. Brown was given stem cells that were predisposed to resist HIV infection, because the donor happened to have a mutated version of a key protein - CCR5 - that is needed for HIV to infect cells. So Brown's transplant was akin to gene therapy with HIV-resistant cells.

But the Boston patients received stem cells without the protective mutation. The transplanted cells must therefore have been protected from infection by the antiretroviral drugs taken during cancer treatment. Their doctors think that an immune response called graftversus-host disease - a post-transplant reaction in which donated cells kill off a patient's own cells — may have then wiped out the patients' HIV reservoirs, potentially curing the men.

Transplant specialist Christine Durand of Johns Hopkins University School of Medicine in Baltimore, Maryland, says that the case of the Boston patients may show that current antiretroviral drugs are powerful enough, on their own, to protect the transplanted cells. "If cure has been achieved in the Boston patients, then it was the antiretroviral therapy, not gene therapy, that protected the donor cells," she says.

The finding is very important for people with HIV who also need blood-cell transplants, but the treatment is unlikely to be used more generally because the risks from transplants are high. Durand says that Johns Hopkins is now revising its transplant procedures to keep people with both cancer and HIV on antiretroviral drugs during the transplant regimen.

Separately, the International Maternal Pediatric Adolescent AIDS Clinical Trials (IMPAACT) Group, based in Silver Spring, Maryland, is trying to replicate the Berlin patient's cure by giving CCR5-mutated HIV-resistant blood from umbilical cords to children and adults with HIV and cancer.

Everyone with HIV could benefit from this work, researchers say, because it could yield valuable information about how to eliminate the HIV reservoir.

"We are still a long way off from a viable cure option for most patients," Durand says. "But every step counts, and these cases can teach us important lessons."

Nature | doi:10.1038/nature.2013.13297 